https://doi.org/10.24201/aap.2021.329

INFORME

\title{
Taiwán: entre la crisis mundial y los aciertos internos
}

\section{Taiwan: Between Global Crisis and Internal Success}

\author{
ITZEL MARTÍNEZ RUIZ \\ https://orcid.org/0000-0001-5760-5404 \\ Universidad Nacional Autónoma de México, México
}

Recepción: 19 de octubre de 2020

Aceptación: 2 de noviembre de 2020

Resumen: El informe de Taiwán abarca los acontecimientos más significativos que moldearon el desarrollo de su política interna, la política externa y su impacto en la economía durante 2020. En este año, la pandemia de covid-19 fue el suceso que cambió el curso de la historia global; en este contexto Taiwán logró enfrentar de forma atinada los retos derivados de la emergencia sanitaria y mostrarse en la esfera mundial como un caso de éxito. Sin embargo, el 2020 también significó un año de múltiples movilizaciones en el estrecho de Taiwán debido a que las tensiones entre China y Estados Unidos situaron nuevamente a Taipéi como una pieza fundamental en el tablero geopolítico entre ambos países.

Palabras clave: pandemia; covid-19; ejercicios militares; crisis del estrecho de Taiwán.

\footnotetext{
Abstract: The report of Taiwan covers the most significant events that shaped the development of domestic policy, foreign policy and its impact on the economy during 2020. The Covid-19 pandemic was the most important event that changed the course of global history. However, Taiwan successfully managed to face the challenges derived from the 
health emergency showed itself as a successful case. However, 2020 also meant a year of multiple mobilizations in the Taiwan Strait, because tensions between China and the United States once again placed Taipei as a fundamental piece on the geopolitical chessboard between both countries.

Keywords: pandemic; Covid-19; military exercises; Strait of Taiwan crisis.

\section{INTRODUCCIÓN}

Para Taiwán, 2020 fue un año de cambios, retos e importantes aciertos. La presidenta Tsai Ing-wen fue reelecta en una contienda desahogada y con un alto grado de aprobación entre la población taiwanesa. En contraparte, para el resto de los partidos políticos y particularmente para la oposición fue un año de constantes divisiones internas. Bajo la administración del presidente Donald Trump, las relaciones bilaterales entre Taipéi y Washington se intensificaron, ocasionando que las tensiones entre la isla y Beijing escalaran al borde de una nueva crisis.

La pandemia de covid-19 cambió el curso de la geopolítica internacional, impactó en las relaciones de la región Asia Pacífico y visibilizó nuevamente el papel de Taiwán en la arena internacional. Entre enero y diciembre el gobierno implementó al menos 124 acciones para frenar y combatir el avance del virus. ${ }^{1}$ Entre los mecanismos de control se implementó el establecimiento de puntos de control fronterizos en el mar y el aire, así como el uso de nuevas tecnologías para la identificación de casos, la cuarentena obligatoria para casos sospechosos, el aumento de las capacidades de los servicios médicos y la asignación de recursos específicos para el manejo y control de la pandemia. Además se realizaron campañas educativas para evitar la desinformación, y la negociación diplomática tuvo un papel preponderante para lograr acuerdos con otros países. Conjuntamente, el rediseño de las políticas educativas y del cuidado infantil, y el desarrollo de planes económicos para apoyar al sector privado. Tales acciones lograron que, en una región de más de 23 millones de

\footnotetext{
${ }^{1}$ Para el manejo de la crisis, el gobierno taiwanés reformuló su manual de estrategias para el manejo de enfermedades transmisibles.
} 
habitantes, durante casi un año de combate a la covid-19, sólo se hayan reportado 799 infecciones y siete decesos resultantes de la enfermedad.

Debido al óptimo manejo de la pandemia, lo que le valió incluso reconocimiento mundial, la presidenta Tsai inició su segundo y último mandato presidencial en mayo de 2020 con altos niveles de popularidad local. Su rápida estrategia de contingencia logró evitar la propagación del virus de SARS-CoV-2 y, en consecuencia, el incremento de decesos derivados de la enfermedad. También impidió que se desplomara la economía local mediante la ejecución de políticas económicas efectivas que incluyeron la designación de recursos para el rescate de las empresas locales y la ejecución de medidas para evitar la paralización de actividades económicas en el momento más álgido de la pandemia.

\section{POLÍTICA INTERNA}

La política interna de Taiwán durante 2020 fue dinámica desde el inicio de año debido a la celebración de las elecciones presidenciales y legislativas, en las cuales el Partido Democrático Progresista (PDP), al que pertenece la presidenta Tsai Ing-wen, arrasó en las urnas. Los partidos políticos locales sufrieron reconfiguraciones y conflictos internos. Además, debido a la pandemia de covid-19 todas las esferas políticas y los ministerios tuvieron que colaborar para dar frente a este reto de salud.

El $1^{\circ}$ de enero, el jefe del Estado Mayor del Ejército de Taiwán, Shen Yi-ming, murió en un accidente aéreo después de que el helicóptero Black Hawk UH-60M en el que viajaba realizara un aterrizaje forzoso en una zona montañosa cerca de la capital. Junto a Shen, otras siete personas perdieron la vida. Entre los muertos se encontraban altos mandos del ejército, incluido el mayor Yu Chin-wen, subdirector de la Oficina de Guerra Política, y el general mayor Hung Hung-chun, quien laboraba en el departamento de Inteligencia del Ministerio de Defensa (Lee y Wu 2020).

Tsai Ing-wen ganó las elecciones y fue reelecta para encabezar su segundo mandato como presidenta de Taiwán el 11 de enero de 2020. Tsai obtuvo 57.13\% de los sufragios para el Partido Democrático Progresista (PDP, 民主進步黨), venciendo a Han Kuo-yu, su principal oponente político, candidato del Kuomintang (KMT, 國民黨), quien sólo obtuvo 
$38.61 \%$ de los votos. Se estima que, aproximadamente, $74.9 \%$ de los electores acudieron a las urnas a emitir su voto. Durante esta contienda, el número de votos obtenidos por Tsai superó los que había conseguido en su elección de $2016^{2}$ (Tiezzi 2020).

En este proceso electoral también fueron votados los 113 legisladores que representan al Yuan Legislativo. Del total de escaños, 73 son elegidos directamente mediante el voto directo en distritos uninominales locales; 34 asientos son designados por representación proporcional, y seis son electos por grupos indígenas taiwaneses. Del total de escaños, el PDP obtuvo 61 (48 de éstos elegidos de forma directa en las votaciones), aproximadamente 53.9\% de los asientos, perdiendo seis en comparación con la elección de 2016. Por su parte, el KMT obtuvo 38, que representa alrededor de 33.6\% del Yuan Legislativo (tres escaños más que en 2016); el Partido del Pueblo de Taiwán (台灣民眾黨) logró cinco, es decir, 4.4\%; el Partido del Nuevo Poder (時代力量) consiguió tres lugares (2.6\%); el Partido de la Construcción del Estado de Taiwán (台灣基進) alcanzó un escaño (2.6\%), y cinco lugares (4.4\%) quedaron en manos de otros candidatos independientes.

Los candidatos del PDP obtuvieron amplias victorias en las seis municipalidades especiales de Taiwán, que comprenden la capital Taipéi, Taoyuan, Taichung, Nuevo Taipéi, Tainan y Kaohsiung. Precisamente en Kaohsiung, donde Han Kuo-yu fungió como alcalde hasta junio de 2020, el PDP ganó todos los distritos electorales. La victoria arrasadora de Tsai es atribuida por varios expertos a factores como la respuesta ciudadana a la crisis que se ha desarrollado en Hong Kong desde junio de 2019, al desarrollo de la guerra comercial entre China y Estados Unidos, al impacto en la isla del discurso pronunciado por el presidente $\mathrm{Xi}$ Jinping en enero de 2019 en relación con la reunificación de China, entre otros.

Ferrán Pérez apunta que la reelección de Tsai fue resultado de la alineación de varios elementos. En primer lugar, es la culminación del proyecto político, geopolítico y socioeconómico de larga duración de Cheng Shui-Bian, proyecto que inició en el año 2000, y consistió en desarrollar una lenta socialización política de la población, principalmente entre los jóvenes. Otro elemento apunta a que los resultados electorales fueron un claro

\footnotetext{
${ }^{2}$ En aquel proceso electoral la presidenta fue elegida con $56.1 \%$ de los votos, alrededor de 6.89 millones, en comparación con los 8.17 millones obtenidos en este plebiscito.
} 
mensaje para China continental, indicando que la presión militar, económica y diplomática ejercida antes y durante la contienda no impactó ni incidió para que ganara el candidato que apoyaba Beijing (Pérez Mena 2020).

El 24 de agosto de 2020 el candidato del PDP Chen Chi-mai ganó las elecciones en la municipalidad sureña de Kaohsiung, luego que Han Kuo-yu fue removido del cargo mediante una histórica votación revocatoria llevada a cabo el 6 junio de 2020. Por primera vez en la historia de autonomía local de Taiwán, un jefe gubernamental en lo local fue destituido. La Comisión Electoral de Kaohsiung estima que aproximadamente $42.13 \%$ del electorado acudió a las urnas, y con 939090 votos (97.4\%) a favor de la destitución, y 25051 (2.6\%) Han fue obligado a dimitir. La petición para la destitución de Han fue promovida por organizaciones civiles locales, luego de que Han anunció su candidatura a la presidencia en junio de 2019, tan sólo seis meses después de que inició su gestión como alcalde (Chen y Hang 2020). A inicios de año, Ko Wen-jen se convirtió en el alcalde de Taipéi, y contendió por el Partido del Pueblo de Taiwán (PPT); esta victoria logró afianzar al partido como la tercera fuerza política del país.

Por su parte, Lai Ching-te, quien fue el principal contendiente de Tsai Ing-wen en el proceso interno del PDP para contender por la presidencia de la isla, fue electo vicepresidente. Las convicciones del vicepresidente y su postura independentista han despertado suspicacia en Beijing, especialmente por el acercamiento que Lai ha tenido con Estados Unidos. El 2 de febrero asistió a título personal al Desayuno de Oración Nacional, una reunión anual organizada por la asociación cristiana en Washington D. C. (Noticias de Taiwán 2020). Empero, Lai aprovechó el viaje para reunirse con organizaciones y diversos grupos de expertos y académicos taiwaneses radicados en Estados Unidos. Conjuntamente mantuvo una reunión con el senador Marco Rubio, así como con integrantes del lobby taiwanés ante el gobierno estadunidense en turno. También visitó el Consejo de Seguridad Nacional, donde fue acompañado por el represente de Taipéi ante Washington, Stanley Kao, así como por Vincent Chao, director de asuntos políticos (Ríos 2020a).

En marzo, el KMT eligió, con aproximadamente 70\% de votos a favor, a Chiang Chichen como el presidente del partido, remplazando a Wu Den-yih, quien dimitió al cargo en enero después de la arrasadora derrota electoral que sufrieron. Es de destacar que sólo fue 
registrado un 35\% de participación entre los simpatizantes del partido. Chiang únicamente contendió contra Hau Lung-bin, quien se desempeñó como alcalde de Taipéi de 2006 a 2014. Asimismo, durante este ejercicio electoral fueron elegidos 32 nuevos miembros del Comité Central Permanente del KMT (Wei 2020).

La victoria de Chiang supone un reto importante al interior del KMT porque siendo un candidato más joven se impuso sobre Hau, quien es un político con una trayectoria más larga y consolidada. Durante su campaña, Chiang indicó que entre sus objetivos estaban la implementación de una nueva estructura organizativa, lograr una mayor descentralización interna, aumentar el aprovechamiento de las redes sociales e incrementar la interacción con el exterior (Ríos 2020b).

El KMT atraviesa por una reforma estructural debido a que los nuevos miembros, especialmente los más jóvenes, buscan tener mayor participación y reorientar la política que los veteranos han seguido, especialmente después de la derrota presidencial y legislativa. Entre los partidos políticos en la isla, el KMT es considerado el más cercano y pro-Beijing debido a que desde 2005 el Partido Comunista Chino (PCC) y el KMT pactaron un acuerdo para frenar los intentos independentistas y fortalecer su colaboración para alcanzar una reunificación pacífica de acuerdo con el "Consenso de 1992”.

La política de la presidenta Tsai es lineal y durante su segundo mandato ha mostrado que continuará desarrollando el proyecto político que inició hace cuatro años. Entre los aspectos más relevantes de su política se identifica la revisión de la relación con Beijing, mantener el statu quo en la región y dejar de lado el proyecto de unificación establecido en el Consenso de 1992 (Ríos 2020c). Empero, uno de los mayores retos que enfrenta durante su nuevo mandato es el anuncio de la octava reforma constitucional. En septiembre de 2020 el gobierno conformó un comité encargado de evaluar y organizar el proceso para lograr la enmienda constitucional. El comité se conformó por 22 legisladores del PDP, 14 legisladores del KMT, dos del PPT y uno del NPP. De este modo, se propusieron once borradores de enmiendas constitucionales, las cuales fueron aprobadas en la última sesión legislativa debido a que tuvieron el respaldo de por lo menos una cuarta parte de los 113 legisladores (Fang y Hsu 2020). 
El vocero del KMT, Hung Yu-chien declaró en julio que la reforma constitucional debería realizarse con el consenso de todos los partidos políticos. Sin embargo, desde su punto de vista, la actual administración no lo ha permitido y "ejerce una tiranía aplastante de la mayoría" en la toma de decisiones (Yang y Xie 2020). Para el KMT la actitud de la presidenta Tsai ha creado un poder extremadamente desigual entre los partidos gobernantes y de oposición sin mostrar respeto por los segundos. En otra declaración, el vocero del KMT señaló que el PDP busca la abolición del examen del Yuan para hacerse de su control, y con ello no evidenciar la incompetencia de Tsai para gobernar la nación y su liderazgo tiránico. Por su parte, el líder del PNP indicó que su partido apoyará la reforma constitucional, y el legislador del PPT Jang Chyi-lu apoyó el acuerdo y mencionó que la abolición de las dos ramas del gobierno y la reducción mínima para votar a los 18 años son apelaciones que su partido ha hecho por mucho tiempo.

\section{EL BROTE DE COVID-19 EN LA ISLA, ACIERTOS Y ERRORES}

Taiwán, una nación de aproximadamente 23 millones de personas, con una densidad poblacional de 668 habitantes por kilómetro cuadrado ha logrado con éxito contener el brote de covid-19 en gran medida gracias a las estrategias y políticas implementadas por un Estado poderoso, con capacidad de movilizar recursos para alcanzar el desarrollo tecnológico y económico. También, gracias a la colaboración de las élites y a la experiencia de una población taiwanesa que por emergencias sanitarias previas respondió de manera responsable y civilizada. Es de destacar que el civismo que se ha observado en Taiwán, China, Japón o Corea del Sur para atender la contingencia está asociado con elementos culturales de responsabilidad individual hacia la comunidad, con la visión confuciana de ser parte de un todo, y con la experiencia colectiva frente a las fuerzas de la naturaleza (Herrera-Feligreras y Pérez Mena 2020).

Fue el 21 de enero de 2020 cuando Taiwán reportó su primer caso confirmado de covid-19, y debido a la cercanía entre Taiwán y China y el alto flujo de personas entre ambas regiones se esperaba que la isla presentara el segundo brote más grande de la región sólo detrás de China. Durante 2019 al menos 2.71 millones de visitantes de China continental arribaron a Taiwán, además, aproximadamente 850000 ciudadanos taiwaneses viven en 
China, y otros 400000 trabajaban o viven en el territorio vecino. A pesar de ello, Taiwán ha sido uno de los pocos casos de éxito que ha logrado evitar la rápida propagación del virus, siendo incluso reconocido mundialmente por implementar las mejores estrategias contra la covid-19.

A partir del brote del síndrome respiratorio severo agudo (SARS) en 2003, Taiwán reforzó sus medidas de respuesta ante emergencias sanitarias. En 2004 el gobierno creó el Centro Nacional de Comando de Salud (NHCC, por sus siglas en inglés). El NHCC es un centro de gestión de desastres que se especializa en analizar y responder a grandes brotes, y funge como el comando operativo para las comunicaciones directas entre las autoridades centrales, regionales y locales. Durante las emergencias este centro unifica un sistema de comando central que incluye al Centro de Comando de Desastres de Patógenos Biológicos, al Centro de Comando Contra el Bioterrorismo, al Centro de Comando Central de Epidemias (CECC, por sus siglas en inglés), y al Centro de Operaciones de Emergencia Médica Central.

Las medidas adoptadas permitieron que, previo al brote de SARS-CoV-2, que ocurrió antes de las festividades del Nuevo Año Lunar chino, las autoridades taiwanesas se movilizaran e implementaran medidas para identificar, contener y destinar recursos para proteger la salud pública. Además robustecieron su base de datos de seguros médicos a nivel nacional e incorporaron información de aspectos migratorios y aduanales para generar un banco de datos a gran escala que facilitara el análisis de la información. Conjuntamente, aprovechando el uso de códigos QR y los reportes en línea de los historiales de viajes de los visitantes de los últimos 14 días, lograron clasificar su riesgo infeccioso (Wang et al. 2020).

El 25 de febrero el Yuan Ejecutivo aprobó un presupuesto de NTD \$60 000 millones con el objetivo de amortiguar el impacto económico derivado del brote de covid-19 en la isla debido a su alta dependencia a las exportaciones. El paquete incluyó además un programa de préstamos para pequeñas empresas, recortes de impuestos para los conductores de autobuses turísticos, subsidios para las agencias de viajes, vales para el consumo en famosos mercados nocturnos, entre otros (Reuters 2020). Por otra parte, en la misma fecha fue promulgada la Ley Especial de Medidas de Prevención, Alivio y Revitalización de la Neumonía Grave con 
Nuevos Patógenos. Los 19 artículos de esta ley se implementaron con el objetivo de regular los esfuerzos de respuesta y ayuda relacionados con la pandemia de covid-19 en Taiwán. ${ }^{3}$

La Organización Mundial de la Salud (OMS) se mostró cautelosa en reconocer la estrategia de Taiwán en su combate contra el covid-19, debido a la tensa relación de la isla con Beijing. Taiwán no ha logrado obtener su membresía en la organización, además ha sido excluida de las reuniones de emergencia, no ha participado en la realización de informes mundiales sobre salud y se le ha negado la autorización para asistir a las reuniones anuales de la Asamblea Mundial de la Salud en los últimos años (BBC 2020).

A mediados de marzo, Taiwán señaló que la OMS no consideró la advertencia temprana sobre la transmisión del virus del SARS-CoV-2 de humano a humano que emitió el 31 de diciembre de 2019. Taipéi calificó la acción de la OMS como desatinada y atribuyó a la organización la ralentización de la respuesta global ante la pandemia. Taipéi informó tanto al Reglamento Internacional de Salud, una dependencia de la OMS para el intercambio de datos de prevención y respuesta a epidemias, como a las autoridades sanitarias chinas. El gobierno taiwanés mencionó que médicos locales habían escuchado de colegas de China continental que personal médico se estaba enfermando, lo que daba indicios tempranos sobre una posible transmisión de persona a persona (Finantial Times 2020).

Por su parte, la OMS exteriorizó que no les fue posible obtener información de primera mano para analizar y confirmar si existía transmisión de covid-19 entre humanos, por lo tanto, el anunció se retrasó. El Ministerio de Salud de China confirmó el descubrimiento el 20 de enero, después de que la OMS indicara que podría haber una transmisión limitada de persona a persona. Desde entonces muchos países, particularmente de Occidente, acusaron al organismo y a Beijing de actuar de manera tardía para prevenir el avance del brote del virus.

A finales de marzo, la televisora de Hong Kong RTHK transmitió una entrevista con el subdirector general de la OMS, Bruce Aylward. Durante el evento, el funcionario de la organización fue cuestionado respecto a la posibilidad de permitir el ingreso de Taiwán a la OMS. Sin embargo, evitó responder a pesar de la insistencia de la periodista Yvonne Tong. Se presume que el funcionario colgó la videollamada después del cuestionamiento, y luego

\footnotetext{
${ }^{3}$ El 21 de abril de 2020 fueron enmendados 11 artículos del acta. https://aw.moj.gov.tw/ENG/LawClass/LawHistory. aspx?pcode $=\mathrm{L} 0050039$
} 
de volver a llamarlo y de insistir en la pregunta, éste respondió que ya se había hablado de China. En redes sociales este acontecimiento generó controversia, ya que la reacción del subdirector general de OMS fue tomada como indicativo de la relación incierta que esta organización mantiene con Taiwán.

Una vez que el 31 de enero la OMS notificó los reportes de neumonía atípica en la ciudad de Wuhan, en la provincia china de Hubei, las autoridades taiwanesas comenzaron a abordar vuelos directos provenientes de esta región para detectar a pasajeros con síntomas de fiebre y neumonía. Para el 5 de enero las autoridades extendieron las medidas y determinaron que todas las personas que hubieran viajado a Wuhan en los 14 días previos, así como pasajeros que mostraban los síntomas mencionados, fueran sujetos a revisión y puestos en cuarentena domiciliaria. El 20 de enero, mientras que en China continental se reportaban casos esporádicos de infecciones, el Centro para el Control de Enfermedades de Taiwán activó el CECC para tratar la neumonía y colaborar en conjunto con el ministro de Salud y el NHCC.

El CECC está facultado para trabajar en coordinación con diversos ministerios, entre ellos el de transporte, de trabajo, de educación, de economía, y la Administración de Protección Ambiental. El 30 de enero la base de datos del NHIA se amplió para cubrir el historial de viajes de pacientes provenientes de China, Macao y Hong Kong, esta información se registra en la tarjeta del Seguro Nacional de Salud (NHI, por sus siglas en inglés), lo que permite al personal de salud identificar casos sospechosos de covid-19. Adicionalmente, el gobierno puso en funcionamiento, en colaboración con las empresas enfocadas en sistemas de telecomunicaciones, un programa para permitir el rastreo mediante GPS de las ubicaciones de los posibles contagiados, estableciendo multas o localización obligatoria a aquellos residentes que infringieran la cuarentena de acuerdo con la legislación (Pu 2020).

El 16 de marzo Taiwán cerró la frontera para los visitantes extranjeros y ordenó que los ciudadanos taiwaneses y residentes extranjeros (incluyendo diplomáticos) guardaran cuarentena obligatoria de 14 días. En el mismo sentido y con el fin de evitar que los trabajadores migrantes del Sudeste Asiático salieran del territorio y regresaran se les permitió extender sus visas, advirtiéndoles que si salían de la isla no podrían reingresar. A los viajeros 
extranjeros con visas temporales se les notificó que no se otorgarían extensiones, visas ni permanencias (Aspinwall 2020b).

Entre finales de julio y principios de agosto, las autoridades identificaron un incremento de casos de covid-19, sin embargo, determinaron que estos casos fueron importados por viajeros que llegaron de otros países asiáticos. En agosto, el ministro de Salud Chen Shih-chung fue criticado por la aparente limitación en la realización de pruebas, después de que fuera abruptamente cancelado un programa de pruebas para la detección de anticuerpos en el condado de Changhua previo a la publicación de los resultados de éste. Conjuntamente, el gobierno fue desacreditado luego de permitir la entrada de una delegación estadunidense liderada por Alex Azar, secretario de Salud y Servicios Humanos, sin someterse a la cuarentena obligatoria de 14 días (Aspinwall 2020c).

Durante la segunda mitad del año, en septiembre y octubre la isla reportó entre uno y tres casos diarios, en algunas ocasiones no había ningún registro. Sin embargo, Taiwán reportó un ligero aumento de los casos confirmados de covid-19 durante los meses de noviembre y diciembre, en los que se registraron los picos más altos de infecciones durante el semestre. Se reportaron 14 casos nuevos el 27 de noviembre, 24 el 30 de noviembre, y 23 el 6 de diciembre. La mayoría de los casos fueron importados, particularmente de viajeros de Indonesia, Estados Unidos, Reino Unido y Filipinas. Por lo anterior, el gobierno instrumentó restricciones migratorias para viajeros que volaban desde Indonesia, específicamente para el ingreso de trabajadores.

\section{EFECTOS ECONÓMICOS DE LA PANDEMIA}

A pesar del brote de covid-19, la economía de Taiwán se mantuvo relativamente estable debido a que el eficaz manejo de la pandemia evitó cierres de emergencia y la instauración de restricciones de movilidad. Las compañías e industrias establecidas en la isla nunca fueron forzadas a cerrar, y pudieron continuar operando con normalidad. Previendo una posible modificación en la cadena de suministros global, el gobierno creó un programa de apoyo para evitar el desplome de la economía mediante el que se otorgaron tres tipos de apoyo: asistencia para el empleo, exenciones fiscales y ayuda financiera. 
Las medidas incluidas como parte de las ayudas financieras fueron el otorgamiento a trabajadores y empresas de préstamos por NTD \$700 000 millones, entre los que se incluyeron NTD \$300 000 millones en préstamos operativos y estímulos a las pequeñas y medianas empresas (PyMES). El gobierno también permitió la subvención a los bancos que redujeron o condonaron los intereses de los antiguos préstamos a las PyMES, y otorgaron préstamos de ayuda a los trabajadores.

Con el objetivo de otorgar asistencia para el empleo, el Ministerio de Trabajo creó planes de trabajo con salarios subsidiados, otorgó seguros de desempleo y brindó subsidios de matrículas escolares para niños cuyos padres estuvieran desempleados. Respecto a los corporativos, la administración garantizó subsidios para mejoras de los entornos laborales, con el fin de mejorar las capacidades de seguridad y salud de los lugares de trabajo. Los programas estaban destinados a las empresas de alto riesgo, principalmente aquellas relacionadas con el área de la salud.

Dentro de las políticas de exenciones fiscales destaca que a las empresas que enfrentaron dificultades operativas debido al brote de covid-19 se les dio la opción de solicitar rembolsos de impuestos comerciales, y las pequeñas empresas fueron exentadas de informar los montos de sus ventas. Los plazos impositivos fueron reducidos para permitir que los contribuyentes solicitaran el aplazamiento o parcialización de pago de impuestos. Otorgaron a las empresas prórrogas para la realización de los pagos referentes al seguro laboral y a las pensiones sin penalización. Mediante los bancos públicos se dieron apoyos de financiamiento a las pequeñas y medianas empresas, y se concedieron prórrogas para el pago de préstamos o para la extensión de éstos. Se permitió el aplazamiento de los pagos de tarjetas de crédito y las tasas de interés fueron reducidas. También fueron negociadas condonaciones y se realizaron reajustes en los pagos de rentas (Executive Yuan 2020).

Las medidas adoptadas favorecieron que, durante el primer cuatrimestre del año, la isla registrara un crecimiento económico de $2.20 \%$, aunque durante el segundo cuatrimestre la economía se contrajo, generando un crecimiento negativo del $-0.58 \%$. De acuerdo con el Departamento de Estadísticas, entre enero y septiembre la producción industrial y manufacturera, que incluye también la minería, la electricidad y el suministro de agua y gas, aumentó 6.98\% en promedio, en comparación con 2019 (Department of Statistics 2020). 
En promedio, entre enero y septiembre las exportaciones aumentaron $9.4 \%$ respecto al año anterior, superando las expectativas del mercado que pronosticaban un alza de 6.6\%. En gran medida, este repunte se explica por el fortalecimiento del comercio de productos electrónicos (26.1\%), productos de telecomunicación, video y audio (22.5\%). De acuerdo con el Ministerio de Finanzas, entre enero y septiembre las exportaciones de Taiwán hacia China continental, incluyendo a Hong Kong, se incrementaron 22.3\% y hacia Estados Unidos $14.5 \%$, comparado con 2019. Por su parte, los efectos de la pandemia fueron tangibles en sus exportaciones a los 18 países que conforman la iniciativa "Nueva Política Hacia el Sur" que sigue Taiwán, ya que tuvieron los niveles más bajos de intercambio en los últimos diez años (Ministry of Finance 2020).

Un factor que favoreció el incremento en sus exportaciones es la guerra comercial en la que se encuentran China y Estados Unidos, debido a que la industria tecnológica china ha sido duramente bloqueada por Washington, lo que ha provocado un importante incremento en la demanda de productos electrónicos producidos en la isla. Entre los efectos de la pandemia se encuentran los cambios en los patrones de consumo y el aumento en el uso de tecnología para el comercio, lo que incrementó la demanda de aplicaciones de comunicación 5G, de dispositivos informáticos de alto rendimiento, de componentes electrónicos y productos asociados con las comunicaciones de la información, y de video componentes.

\section{POLÍTICA EXTERIOR}

Hasta finales de 2019, la política exterior de Taiwán estaba limitada a mejorar la relación con sus únicos 15 aliados en todo el mundo. Sin embargo, en 2020 su imagen mejoró y su manejo de la pandemia le permitió regresar a los titulares en todo el mundo. Varios países se acercaron a la actual administración para intercambiar experiencias en el control del brote de SARS-CoV-2, y la presidenta Tsai aprovechó la coyuntura para poner en marcha la diplomacia de las mascarillas, la cual consistió en realizar donaciones de al menos 50 millones de unidades, destinando alrededor de 10 millones a Estados Unidos. 


\section{Relación bilateral con Estados Unidos}

Durante 2020 las tensiones entre Beijing y Washington alcanzaron su punto más álgido, llevando esta relación bilateral al mayor deterioro en los últimos 70 años, incluso la retórica y acciones implementadas por ambos se asemejan a los eventos vividos durante la Guerra Fría. La administración del presidente Donald Trump ha acusado severamente a China de ser la causante de la pandemia de covid-19 y, desde su perspectiva, por el inadecuado manejo que el gobierno chino ha tenido de ésta. La escalada en la guerra comercial ha provocado que ambos países impusieran una serie de nuevos aranceles y sanciones económicas mutuas que han perjudicado principalmente al sector tecnológico.

A lo largo del año, ambas potencias estuvieron envueltas en conflictos diplomáticos debido a las sanciones que Estados Unidos impuso a Beijing en respuesta a las medidas que China implementó para frenar las protestas llevadas a cabo en Hong Kong, llegando a su punto más crítico con la aprobación e implementación de la Ley de Seguridad Nacional en junio, así como por las acusaciones realizadas por Estados Unidos referentes a la supuesta violación de los derechos humanos a la minoría étnica Uigur, en la Región Autónoma de Xinjiang.

En medio de este escenario Taiwán retomó su posición como un elemento clave en los conflictos geopolíticos entre Beijing y Washington, debido a que el presidente Donald Trump empleó el asunto de Taiwán como un mecanismo de presión hacia China. Taipéi se benefició por los conflictos entre ambas potencias, porque a consecuencia de éste, la política del presidente Trump buscó fortalecer su relación bilateral con la isla, situando a China como su principal rival.

Durante el 2020 el presidente Trump recurrió a una política exterior más agresiva hacia China, muestra de ello fue la felicitación pública que le hizo a la presidenta Tsai, luego de que ella ganara las elecciones. Su administración también buscó impulsar a Taiwán para que acrecentara su participación en organismos internacionales, incluyendo la Asamblea Mundial de la Salud (WHA, por sus siglas en inglés) y en la Organización de las Naciones Unidas (ONU). 
El 4 marzo la Cámara de Representantes aprobó por unanimidad la Ley de Iniciativa de Protección y Mejora Internacional de los Aliados de Taiwán (conocida como TAIPEI, por sus siglas en inglés), la cual fue previamente aprobada por el Senado en octubre de 2019. Esta acta fue escrita y propuesta por el senador republicano por Colorado Cory Gardner en mayo de 2019, y por el senador demócrata por Delaware Chris Coons. Una vez aprobada, el 27 de marzo, el presidente Donald Trump firmó y aprobó la inmediata ejecución de la ley (Zhou 2020). Esta ley le autoriza al Departamento de Estado de los Estados Unidos reducir sus compromisos de seguridad, económicos, y diplomáticos con las naciones que toman acciones significativas o serias para socavar la soberanía de Taiwán. Además promueve una mayor cooperación entre Estados Unidos y Taiwán, y busca que Taipéi figure en organismos internacionales, como miembro u observador (Kuo 2020).

En julio, Taiwán nombró a Hsiao Bi-khim, ex legisladora del PDP, como su nueva representante en su embajada de facto en Estados Unidos. Hsiao fungió como asesora del Consejo de Seguridad Nacional y se convirtió en la primera mujer en representar a la isla en Washington. Su nombramiento fue bien recibido por Estados Unidos debido a su larga trayectoria, su involucramiento en las relaciones bilaterales, su experiencia en asuntos internacionales, así como por su formación en este país (Wen et al. 2020).

El 23 de julio el Senado de Estados Unidos aprobó la versión para 2021 de la Ley de Autorización de Defensa Nacional (NDAA, por sus siglas en inglés), en la que se autorizaron asignaciones y se establecieron políticas para reforzar la colaboración con Taipéi por medio de acciones que incluyen el fortalecimiento de su ejército con la venta de armas y el intercambio de oficiales de defensa, así como la realización de ejercicios militares. Asimismo, se plasmó que la cooperación bilateral en la lucha para frenar el avance de la pandemia de covid-19 sería consolidada. Conjuntamente, las disposiciones que incluyen a Taiwán reiteraron que la Ley de Relaciones con Taiwán y las Seis Garantías proporcionadas por Washington en $1982^{4}$ serán la base de las relaciones entre Estados Unidos y Taiwán (Chiang y Ko 2020).

\footnotetext{
${ }^{4}$ Las Seis Garantías fueron otorgadas por el ex presidente Ronald Reagan en 1982, e incluyen una cláusula que garantiza que Estados Unidos no fijará una fecha para poner fin a la venta de armas a Taiwán y que no desempeñará un papel de mediación entre Beijing y Washington.
} 
En julio, el congresista Ted S. Yoho, miembro del subcomité de asuntos asiáticos, presentó ante la Cámara de Representantes la Ley de Prevención de Invasiones de Taiwán, que autoriza a Estados Unidos a emplear su fuerza militar en caso de que China invada la isla. El 19 de septiembre, el senador Rick Scott promovió esta ley ante el Senado que, de acuerdo con Scott, busca proteger a Taiwán del aumento en las presiones y agresiones del Partido Comunista Chino (PCC) (Cheng 2020). La ley establece la autorización defensiva limitada para que el presidente, en caso de un ataque armado, use la fuerza militar con el objetivo de proteger y salvaguardar a Taiwán. También instaura diálogos de seguridad y ejercicios militares combinados y busca que China renuncie a la amenaza o uso de la fuerza militar en su relación con la isla. Con esta iniciativa, Estados Unidos impulsa a Taiwán para que destine recursos internos adicionales a su propia defensa, considerando la compra de armas defensivas asimétricas y el compromiso de la isla con Estados Unidos en actividades de defensa cibernética (Yoho 2020).

El 9 agosto, buscando promover la cooperación entre Taiwán y Estados Unidos en materia de salud para combatir la pandemia de covid-19, el secretario de Salud y Servicios Humanos, Alex Azar, realizó una visita de alto nivel a Taiwán, la primera de un funcionario de nivel de gabinete desde 2014. Posteriormente, el 18 de septiembre, Keith Krach, subsecretario de Estado para el Crecimiento Económico, Energía y Medio Ambiente, arribó a la isla en representación del Departamento de Estado para asistir a un servicio conmemorativo del ex presidente Lee Teng-hui (Qin 2020).

El 21 de octubre Washington acordó venderle a Taipéi tres tipos de sistemas de armas, que incluían 135 misiles de crucero AGM-84H SLAM-ER guiados con precisión y lanzados desde aire. Además aprobó la venta de seis cápsulas de reconocimiento aéreo MS-110 y 11 lanzacohetes ligeros móviles M142, con un valor de 1800 millones de dólares (France 24 2020). El 26 de octubre el Departamento de Estado de Estados Unidos aprobó la venta de misiles a Taiwán para mejorar su capacidad defensiva ante una posible flota de invasión por parte de China en el estrecho de Taiwán. Taipéi solicitó la venta de 100 lanzadores de defensa costera montados sobre camiones y de 400 misiles antibuque tipo Harpoon de la Armada de Estados Unidos (Stashwick 2020a). El 4 de noviembre el gobierno de Taiwán acordó la adquisición de cuatro drones aéreos, con un valor de 600 millones de dólares, y el 7 de 
diciembre ambos gobiernos negociaron la venta de un sistema de comunicaciones de información sobre terreno valuado en 280 millones de dólares.

El 20 de noviembre Taiwán y Estados Unidos realizaron una reunión de alto nivel bajo un nuevo esquema de cooperación económica presenciado por el viceministro de Asuntos Económicos, Chen Chernchyi, y el subsecretario de Estado de Estados Unidos, Keith Krach. Durante la reunión fue firmado un memorándum de entendimiento a plazo de cinco años en el que ambas partes establecieron grupos de trabajo en materia de ciencias y tecnología, seguridad de salud global, telecomunicaciones, desarrollo de la 5G, empoderamiento de la mujer, cooperación en infraestructura, inversión y cadena de suministros. El memorándum no creó obligaciones o derechos legales en ninguna de las partes, y está sujeto a disponibilidad de recursos (Davidson 2020).

\section{Relación con la República Popular China}

A lo largo del año, las tensiones entre Beijing y Taipéi se fueron incrementado de forma escalada, derivando en el despliegue de las fuerzas militares chinas cerca del estrecho de Taiwán a modo de advertencia en múltiples ocasiones, lo cual llevó la relación al borde de una crisis. En su interpretación del Consenso de 1992 y el Principio de una sola China, Beijing nunca ha renunciado al uso de la fuerza para lograr la reunificación, y para el presidente Xi Jinping el asunto de la isla es primordial en su proyecto de nación.

En junio, el gobierno chino implementó la Ley de Seguridad Nacional en Hong Kong con el fin de detener el avance de las protestas antigubernamentales que azotaron al centro financiero desde 2019, y de proteger la seguridad y soberanía nacional. Empero, para muchos expertos su creación también fue un claro mensaje para Taiwán y Estados Unidos debido a la nueva dinámica de su relación bilateral.

El 10 de febrero el Comando del Teatro Oriental del Ejército Popular de Liberación (EPL) envió sus bombarderos y aviones de combate cerca de Taiwán. En respuesta, la Fuerza Aérea de la isla envió cazas para seguir a las aeronaves chinas, y los aviones chinos cruzaron brevemente la línea media no oficial en el estrecho de Taiwán. China declaró que estas acciones estaban asociadas a los simulacros de asalto aire-tierra realizados por el EPL, con el 
objetivo de refinar y probar sus capacidades de combate. Ante estas acciones, el ministro de Relaciones Exteriores de Taiwán solicitó a Beijing que detuviera sus amenazas y que se enfocara en controlar la pandemia de covid-19; sin embargo, las intrusiones de Beijing continuaron durante los siguientes meses.

En marzo, aviones de control y alerta temprana aerotransportados KJ-500 y cazas J11 chinos volaron cerca del suroeste de Taiwán en ejercicios nocturnos y se acercaron a la Zona de Identificación de Defensa Aérea (ADIZ, por sus siglas en inglés) de Taiwán. En respuesta, Taiwán desplegó sus aviones de combate F-16. En abril, el portaaviones chino Liaoning y otros cinco buques de guerra fueron avistados navegando cerca del estrecho de Miyako, entre ellos dos buques de guerra multiuso, dos destructores de misiles guiados y un barco de apoyo de combate rápido de clase de suministro (Rajagopalan 2020).

El 9 de junio el Ministerio de Defensa Nacional confirmó que varios aviones cazas chinos Sukhoi Su-30 sobrevolaron brevemente la ADIZ del suroeste de la isla. Además, un avión de transporte de la marina de Estados Unidos, un C-40A, también ingresó momentáneamente en el espacio aéreo de Taiwán (este avión es la versión militar del avión Boeing 737-700C).

Taiwán realizó en julio su simulacro militar anual, denominado Han Kuang, para revisar sus estrategias defensivas y evaluar sus capacidades de combate en las zonas costeras. Durante el evento fueron disparados misiles simulando un ataque del EPL contra centros de mando, bases militares de Taiwán y aeropuertos. La base aérea subterránea Chiashan ubicada en Hualien fue parte clave del simulacro. También fueron probados aviones de combate Mirage 2000 y F-16, así como aviones de patrulla de guerra antisubmarina P-3C, buques de guerra y submarinos (Chung 2020a).

Durante ese mes Taiwán abrió la Oficina de Intercambio y Servicios Taiwán-Hong Kong en respuesta al incrementó de solicitudes de asistencia humanitaria de los habitantes del centro financiero, con el propósito de ayudar a las personas que se encontraban huyendo de Hong Kong, luego de la creación de la Ley de Seguridad Nacional. Esta oficina servirá como un centro en el que un grupo de trabajo brindará asistencia a los habitantes hongkoneses 
que deseen permanecer en Taiwán (Aspinwall 2020d). ${ }^{5}$ Aunque Taiwán no cuenta con una ley de refugiados formal, la oficina creada se basará en el artículo 18 de la Ley de Reglamentos sobre Asuntos de Hong Kong y Macao, que le permite brindar asistencia necesaria a las personas de estas dos regiones, cuando su seguridad y libertad están amenazadas debido a factores políticos.

En agosto China anunció la realización de ejercicios militares en la costa, desde el golfo de Bohai hasta el mar del Este, el Mar de China Meridional y el Mar Amarillo debido a los riesgos de seguridad en el estrecho. El 10 de agosto Beijing desplegó aviones de combate que cruzaron momentáneamente la línea media del estrecho de Taiwán. El 13 agosto la fuerza aérea detectó aviones chinos J-10 y J-11 en el estrecho, y también en el norte y sur de la isla (Zheng 2020a) debido a la visita del secretario de Salud de Estados Unidos. El portavoz del comando chino, el coronel mayor Zhang Chunghui indicó que los ejercicios fueron una medida necesaria para salvaguardar la soberanía nacional, luego de que algunas potencias importantes persistieron en una tendencia negativa sobre el tema de Taiwán (Zheng 2020b).

Durante los primeros días de septiembre, China realizó simulacros aéreos frente a las costas del suroeste de Taiwán. Los voceros de Taipéi indicaron que los cazas avanzados Su30 y J-10 del EPL realizaron los simulacros cerca de la isla $\operatorname{Pratas}^{6}$ e ingresaron en la ADIZ. (Stashwick 2020b). Asimismo, el 23 de septiembre China lanzó dos misiles, entre ellos un "portaaviones asesino" en el Mar de China Meridional. Esta medida se produjo un día después de que Beijing reportó que un avión espía U-2 estadunidense ingresó a una zona de exclusión aérea sin autorización durante un simulacro naval chino en el mar de Bohai. Un misil DF-26B ${ }^{7}$ fue lanzado desde la provincia de Qinghai, y un DF-21D ${ }^{8}$ despegó desde la

\footnotetext{
${ }^{5}$ Desde que iniciaron las protestas en 2019, la presidenta Tsai ha mostrado una postura en favor del movimiento; sin embargo, su administración enfrentó críticas por no haber implementado mecanismos de ayuda directa para los manifestantes.

${ }^{6}$ En las islas Pratas se encuentra una pista de aterrizaje, y allí vive una pequeña población militar y civil. La isla se localiza alrededor de 200 millas náuticas de la costa suroeste de Taiwán, en el Mar de China Meridional.

${ }^{7}$ El misil DF-26 de doble capacidad es un tipo de arma prohibida por el tratado del Tratado de Fuerzas Nucleares de Alcance Intermedio firmado por Estados Unidos y la Unión Soviética cuando finalizó la Guerra Fría. Cuando Estados Unidos se retiró del tratado el año pasado, citó el despliegue de armas por parte de China como justificación. El DF-26 tiene un alcance de 4000 kilómetros (2 485 millas) y se puede utilizar en ataques nucleares o convencionales contra objetivos terrestres y navales.

${ }^{8}$ El DF-21 tiene un alcance de alrededor de 1800 kilómetros, y los medios estatales lo describen como el más avanzado de la serie. El DF-21D es considerado el primer misil balístico antibuque del mundo.
} 
provincia de Zhejiang. Ambos misiles fueron disparados con dirección a las islas Paracel y hacia la provincia de Hainan.

El 24 de septiembre el ejército taiwanés probó misiles frente a sus costas del sur y este, estos ejercicios fueron parte de un programa de dos días realizado por el Instituto Nacional de Ciencia y Tecnología de Chung-Shan para evaluar el poder de los misiles lanzados desde el condado de Taitung y la base militar de Jiupeng localizada en el condado de Pingtung. La Agencia Central de Noticias (CNA, por sus siglas en inglés) citó a un funcionario retirado quien indicó que probablemente los misiles lanzados fueron Tien Kung3 (Sky Bow-3). Estos ejercicios fueron precedidos por numerosas incursiones de identificación de defensa aérea realizados por aviones de combate del EPL, incluidos los aviones de combate Jian-10 y el Sukhoi Su-30, que fueron identificados en el sureste de la isla (Chung 2020b).

\section{Relación de Taiwán con el resto del mundo}

En julio Taiwán firmó un acuerdo con la República de Somalilandia, ${ }^{9}$ para establecer oficinas de representación mutuas (South China Morning Post 2020a). Ambas regiones acordaron establecer oficinas representativas correspondientemente. Se espera que su relación pueda estimular la cooperación en agricultura, pesca, minería, salud, educación y energía. El portavoz del Ministerio de Relaciones Exteriores de China, Zhao Lijian, acusó a las autoridades de Taiwán de planear actividades separatistas, así como de violar la integridad y soberanía territorial de Somalia al establecer oficinas de representación en este territorio.

Del 30 de agosto al 4 de septiembre, una delegación de 89 miembros de líderes políticos y sociales de la República Checa liderada por el presidente del Senado, Milos Vystrcil, visitaron Taiwán, siendo la delegación checa más grande en visitar la isla desde 1989. La atención pública se enfocó en él, debido a que, durante su discurso ante el Yuan

\footnotetext{
${ }^{9}$ Una región africana autónoma que carece de reconocimiento internacional y que no tiene relaciones diplomáticas oficiales con ningún país. En 1991 los clanes que se ubicaban en el norte de Somalia se separaron y crearon el Estado de Somalilandia. A pesar de carecer de reconocimiento internacional, esta región tiene su propia moneda, un gobierno independiente y un sistema de seguridad.
} 
Legislativo, Vystrcil dijo "soy taiwanés". En su visita recibió una medalla honorífica de su homólogo You Shyi-kun para reconocer su apoyo a Taiwán (Chung 2020c).

El gobierno chino condenó la visita realizada por Vystrcil y la calificó como una grave violación de la soberanía nacional de China. ${ }^{10}$ La embajada china en Praga declaró que este incidente representaba una seria interferencia en los asuntos internos de China. El primer ministro chino Wang Yi describió el viaje como una provocación, y amenazó con que Vystrcil pagaría un alto precio por tal comportamiento (South China Morning Post 2020b). El presidente checo, Milos Zeman, acusó al presidente del Senado de una provocación juvenil por visitar Taiwán y dijo durante una entrevista que la opinión de Vystrcil no representaba la opinión mayoritaria de los altos funcionarios del país y había puesto en peligro a las empresas nacionales al someterlas a represalias impuestas por China. ${ }^{11}$

En septiembre, la Unión Europea registró en su página web de la Alianza Internacional de Alcaldes para el Clima y la Energía las ciudades de Taipéi, Nuevo Taipéi, Taoyuan, Tainan, Taichung, y Kaohsiung como parte de Taipéi Chino, que es el nombre que Taiwán utiliza en varios eventos internacionales. Previamente las ciudades estaban registradas como parte de la República Popular China. Este cambio se registró luego de que los gobiernos municipales de las seis ciudades involucradas protestaran por ser consideradas parte de China y amenazaron con abandonar la organización (La Gran Época 2020).

\section{CONCLUSIÓN}

Para la presidenta Tsai Ing-wen y para su partido, 2020 fue un año favorable para el fortalecimiento de su gobierno y su posición política, así como para la consolidación de su proyecto de nación. Sin embargo, al hacer un balance sobre los aciertos que el gobierno de Taiwán tuvo durante 2020, sin duda, el que más destaca fue el manejo adecuado de la pandemia de covid-19 debido a que las estrategias puestas en marcha por el gobierno lograron evitar el rápido avance del virus en su territorio, y resultó en uno de los casos de éxito más

\footnotetext{
${ }^{10}$ El gobierno de la República Checa, que es de centro izquierda, acepta oficialmente la política de Una Sola China; sin embargo, Milos Vystrcil es miembro de la oposición de derecha y no está sujeto al protocolo.

${ }^{11}$ Después de la visita de Milos Vystrcil, la compañía productora de piano Petrof perdió una venta valuada en USD 237000 de un cliente en Beijing.
} 
notables en el mundo. Conjuntamente, el gobierno llevó de la mano políticas para proteger la economía nacional y evitar una fuerte caída de ésta. Además le permitió a la isla visibilizarse y participar en foros y organismos internacionales.

La pandemia de covid-19 aceleró el deterioro de la economía internacional, frenó la migración, incrementó la cifra de desempleo, dañó gravemente el comercio, el consumo y el turismo internacional, y ha empujado a millones de personas a la pobreza. Entretanto, aceleró la dependencia de los seres humanos a las tecnologías, y a las redes sociales, y cambió los patrones de consumo de la población.

De la misma forma, la pandemia ha tenido un impacto de gran alcance en la arena internacional derivado de los efectos económicos, políticos y sociales que ocasionó. La pandemia está transformando las relaciones humanas, las relaciones de poder y la geopolítica internacional. Debido a que el brote de SARS-CoV-2 tiene su origen aparente en China, varios países han criticado algunas de las estrategias que el gobierno chino puso en marcha para frenar el avance del virus, principalmente de Estados Unidos, generando fricciones diplomáticas.

Aunado a lo anterior, la guerra comercial y tecnológica, los conflictos en el sur del Mar de China, la cuestión en el estrecho de Taiwán y los choques derivados de las protestas en Hong Kong deterioraron la relación bilateral entre China y Estados Unidos. La política exterior del presidente Donald Trump se enfocó en reforzar sus relaciones bilaterales por encima del multilateralismo y, considerando la coyuntura con China, durante 2020 fortaleció su relación con Taipéi. Sin embargo, después de que las elecciones presidenciales en Estados Unidos fueron ganadas por Joseph Robinette Biden Jr., podría haber algunos ligeros cambios en la política de Washington hacia la isla. Referente a su relación con China, las tensiones aumentaron a lo largo del año, y se espera que, en el mediano a largo plazo, Beijing tendrá una política más agresiva para consolidar su proyecto de unificación con Taiwán.

Itzel Martínez Ruiz es licenciada en Relaciones Internacionales por la Universidad de las Américas Puebla (UDLAP), es maesta en Estudios de Asia y África, con especialidad en China, por El Colegio de México, y estudiante de doctorado en la Universidad Nacional Autónoma 
de México, en el posgrado de Ciencias Políticas y Sociales con especialidad en Relaciones Internacionales. Sus principales líneas de investigación se enfocan en política exterior, geopolítica, seguridad energética y alimentaria de China.

itmartinezr13@gmail.com

\section{REFERENCIAS}

Aspinwall, Nick. 2020a. "Taiwan Passes Anti-Infiltration Act Ahead of Election Amid Opposition Protest.” The Diplomat, enero 3, 2020. https://thediplomat.com/2020/01/ taiwan-passes-anti-infiltration-act-ahead-of-election-amid-opposition-protests/

Aspinwall, Nick. 2020b. "Taiwan Closes Borders in Preparation for Possible 'Second Wave' of the Coronavirus." The Diplomat, marzo 20, 2020. https://thediplomat.com/ 2020/03/taiwan-closes-borders-in-preparation-for-possible-second-wave-of-thecoronavirus/

Aspinwall, Nick. 2020c. “Taiwan's Covid-19 Success Story Continues as Neighbors Fend Off New Outbreaks." The Diplomat, septiembre 11, 2020. https://thediplomat. com/2020/09/taiwans-covid-19-success-story-continues-as-neighbors-fend-off-newoutbreaks/

Aspinwall, Nick. 2020d. "Taiwan Opens Office to Help People Fleeing Hong Kong in Wake of National Security Law." The Diplomat, julio 2, 2020. https://thediplomat. com/2020/07/taiwan-opens-office-to-help-people-fleeing-hong-kong-in-wake-ofnational-security-law/

BBC. 2020. “Coronavirus por qué Taiwán es un 'dolor de cabeza' para la OMS pese a que ha logrado contener el brote de covid-19.” BBC, abril 1, 2020. www.bbc.com/mundo/ noticias-internacional-52101470

Chen Chun-hua y Julio Yang. 2019. "Proyecto de ley anti-infiltración fue aprobado en medio de protestas." Obervatorio de la Política China, diciembre 31, 2019. https://politicachina.org/areas/taiwan/proyecto-de-ley-anti-infiltracion-fue-aprobado-en-medio-deprotestas 
Chen Yi-hsuan y Luis Hang. 2020. "Kaohsiung Han Kuo-yu destituido de su cargo." Observatorio de la Política China, junio 6, 2020. https://politica-china.org/ areas/taiwan/alcalde-de-kaohsiung-han-kuo-yu-destituido-de-su-cargo

Cheng, Ching-Tse. 2020. "US senator introduces Taiwan Invasion Prevention Act." Taiwan News, septiembre 19, 2020. www.taiwannews.com.tw/en/news/4012435

Chin-yeh, Chiang y Ko Lin. 2020. "US Senate passes 2021 NDAA, with provision to support Taiwan." Focus Taiwan, julio 24, 2020. https://focustaiwan.tw/politics/ $\underline{202007240006}$

Chung, Lawrence. 2020a. “Taiwan's military tests defenses against mainland China invasion in annual war games." South China Morning Post, julio 13, 2020. www.scmp.com/ news/china/military/article/3092984/taiwans-military-tests-defences-against$\underline{\text { mainland-china-invasion }}$

Chung, Lawrence. 2020b. "Tensions rise across the Taiwan Strat as Taipei test-fires missiles." South China Morning Post, septiembre 25, 2020. www.scmp.com/ news/china/military/article/3102990/tensions-rise-across-taiwan-strait-taipei-test$\underline{\text { fires-missiles }}$

Chung, Lawrence. 2020c. “Taiwanese hurt by Czech politician's about-face after warm visit. 'I never called Taiwan an independent state'." South China Morning Post, septiembre 1, 2020. www.scmp.com/news/china/diplomacy/article/3101253/taiwanese-hurtczech-politicians-about-face-after-warm-visit-i

Davidson, Helen. 2020. "US and Taiwan sign five-year agreement on health, tech and security." The Guardian. www.theguardian.com/world/2020/nov/21/us-and-taiwansign-five-year-agreement-on-health-tech-and-security

Department of Statistics. 2020. https://ww.moea.gov.tw/MNS/dos_e/content/ContentLink. aspx?menu id=6748

Executive Yuan, Republic of China (Taiwan). 2020. "Taiwan's covid-19 relief measures." https://english.ey.gov.tw/News3/9E5540D592A5FECD/09d1d995-fe7f-45b8-89ee$\underline{6 \mathrm{a} 42 \mathrm{~d} 279 \mathrm{a} 280}$ 
Fang, Cheng-hsiang y Elizabeth Hsu. 2020. "Legislature decides to set up constitutional amendment." Focus Taiwan, septiembre 14, 2020. https://focustaiwan.tw/ politics/202009140022

Financial Times. 2020. "Taiwan says WHO failed to act on coronavirus transmission warning." Financial Times, marzo 9, 2020. www.ft.com/content/2a70a02a-644a11 ea-a6cd-df28cc3c6a68

France 24. 2020. "US to sell air-to-ground missiles to Taiwan." France 24, octubre 22, 2020. www.france24.com/en/live-news/20201022-us-to-sell-air-to-ground-missiles-totaiwan

Herrera-Feligreras, Andrés y Ferrán Pérez Mena. 2020. “Lecciones de Taiwán en el combate contra el coronavirus: entre la política y la experiencia colectiva." Observatorio de la Política China, marzo 18, 2020. https://politica-china.org/areas/sociedad/leccionesde-taiwan-en-el-combate-contra-el-coronavirus-entre-la-politica-y-la-experienciacolectiva

Kuo, Mercy A. 2020. "Trump and the TAIPEI Act." The Diplomat, abril 21, 2020. https://thediplomat.com/2020/04/trump-and-the-taipei-act/

La Gran Época. 2020. “Taiwán agradece a UE su apoyo para no considerar sus ciudades parte de China." The Epoch Times, septiembre 28, 2020. https://es.theepochtimes. com/taiwan-agradece-a-ue-su-apoyo-para-no-considerar-sus-ciudades-parte-dechina 731648.html

Lee, Yimou y Felice Wu. 2020. “Taiwan's military chief among eight dead in helicopter crash.” Reuters, enero 1, 2020. www.reuters.com/article/us-taiwan-military-missing/ taiwans-military-chief-among-eight-dead-in-helicopter-crash-idUSKBN1Z102B

Ministry of Finance, Republic of China (Taiwan). 2020. Trade Statistics Database. http://web02.mof.gov.tw/njswww/webmain.aspx?sys=100\&funid=edefjsptg1

Noticias de Taiwán. 2020. "Vicepresidente electo asistirá a desayuno de oración nacional de Estados Unidos." Noticias de Taiwán, abril 2, 2020. https://noticias.nat.gov.tw/ news.php? unit $=92 \&$ post $=170473$ 
Pérez Mena, Ferrán. 2020. “La victoria electoral de Tsai Ing-Wen: ¿La venganza de Chen Shui-Bian?" Observatorio de la Política China, enero 11, 2020. https://politicachina.org/areas/taiwan/la-victoria-electoral-de-tsai-ing-wen-la-venganza-de-chen$\underline{\text { shui-bian }}$

Pu, Victor (Lin). 2020. "The Coronavirus Outbreak: how Democratic Taiwan Outperformed Authoritarian China." The Diplomat, febrero 27, 2020. https://thediplomat.com/2020/ $\underline{02 / \text { the-coronavirus-outbreak-how-democratic-taiwan-outperformed-authoritarian- }}$ $\underline{\text { china/ }}$

Qin, Amy. 2020. “US Official Visits Taiwan, and China Warns of Consequences.” The New York Times, septiembre 17, 2020. www.nytimes.com/2020/09/17/world/asia/usofficial-taiwan-china.html

Rajagopalan, Rajeswari Pillai. 2020. “China’s Worrying Military Exercises Near Taiwan.” The Diplomat, abril 17, 2020. https://thediplomat.com/2020/04/chinas-worryingmilitary-exercises-near-taiwan/

Reuters. 2020. "Taiwan passes \$2 billion package to soften coronavirus hit to economy." Reuters, febrero 25, 2020. www.reuters.com/article/us-china-health-taiwaneconomy-idUSKCN20J0N8

Ríos, Xulio. 2020a. "Lai la lía.” Observatorio de la Política China, febrero 8, 2020. https://politica-china.org/areas/taiwan/lai-la-lia

Ríos, Xulio. 2020b. “KMT: relevo generacional.” Observatorio de la Política China, marzo 7, 2020. https://politica-china.org/areas/taiwan/kmt-relevo-generacional

Ríos, Xulio. 2020c. “Taiwán: Tsai II.” Observatorio de la Política China, mayo 21, 2020. https://politica-china.org/areas/taiwan/taiwan-tsai-ii

South China Morning Post. 2020a. "Taiwan and Somaliland establish diplomatic ties, bucking pressure from China." South China Morning Post, julio 6, 2020. www. scmp.com/news/world/africa/article/3092056/taiwan-and-somaliland-establishdiplomatic-ties-bucking-pressure 
South China Morning Post. 2020b. "Beijing says Czech visit to Taiwan harmed its sovereignty and was a serious interference in China's internal affairs." South China Morning Post, septiembre 6, 2020. www.scmp.com/news/china/politics/article/ $\underline{3100401 / \text { beijing-says-czech-visit-taiwan-harmed-its-sovereignty-and-was }}$

Stashwick, Steven. 2020a. "US Approves Sales of Anti-Ship Cruise Missiles to Taiwan." The Diplomat, octubre 29, 2020. https://thediplomat.com/2020/10/us-approves-sales-ofanti-ship-cruise-missiles-to-taiwan/

Stashwick, Steven. 2020b. "Chinese Jets Intrude Taiwan Air Defense Zone for Second Day." The Diplomat, septiembre 11, 2020. https://thediplomat.com/2020/09/chinese-jetsintrude-taiwan-air-defense-zone-for-second-day/

Taiwan News. 2020. “DPP Retains majority in Taiwan elections.” Taiwan News, enero 11, 2020. www.taiwannews.com.tw/en/news/3855186

Tiezzi, Shannon. 2020. “Taiwan 'Shouts Back': President Tsai Wins Re-Election Despite China's Pressure Campaign.” The Diplomat, enero 12, 2020. https://thediplomat. com/2020/01/taiwan-shouts-back-president-tsai-wins-re-election-despite-chinaspressure-campaign/

Wang, Jason et al. 2020. "Response to Covid-19 in Taiwan, Big Data Analytics, New Technology, and Proactive Testing." Journal of the American Medical Association 323 (14). https://jamanetwork.com/journals/jama/fullarticle/2762689

Wei, Katherine. 2020. "Taiwanese lawmaker Chiang Chi-chen wins Kuomingtang chairman re-elecion." Straits Times, marzo 7, 2020. www.straitstimes.com/asia/eastasia/lawmaker-chiang-chi-chen-wins-kuomintang-chairman-re-election

Wen, Kuei-hsiang et al. 2020. “Taiwan's new envoy to US to push for trust-based partnership." Focus Taiwan, julio 7, 2020. https://focustaiwan.tw/politics/ $\underline{202007110008}$

Yang, Chung-hui y Dennis Xie. 2020. "Constitutional reform crucial: Tsai.” Taipei Times, julio 20, 2020. www.taipeitimes.com/News/front/archives/2020/07/20/2003740220 
Yoho, Ted. 2020. "Yoho Introduces Taiwan Invasion Prevention Act." Julio 19, 2020. https://yoho.house.gov/media-center/press-releases/yoho-introduces-taiwaninvasion-prevention-act

Zheng, Sarah. 2020a. "Fighter jets cross a line in Taiwan Strait, says Taipei as it hosts US health official amid rising US-China tensions." South China Morning Post, agosto 10, 2020. www.scmp.com/news/china/military/article/3096776/fighter-jets-crossline-taiwan-strait-says-taipei-it-hosts-us

Zheng, Sarah. 2020b. "Chinese military held drills near Taiwan as US health secretary visited Taipei, PLA says." South China Morning Post, agosto 13, 2020. www.scmp.com/ news/china/military/article/3097218/chinese-military-held-drills-near-taiwan-ushealth-secretary

Zhou, Cissy. 2020. "Donald Trump signs TAIPEI Act to support Taiwan's international relations." South China Morning Post, marzo 27, 2020. www.scmp.com/ news/china/diplomacy/article/3077192/donald-trump-signs-taipei-act-supporttaiwans-international 